\title{
BMJ Open 'Lines in the sand': an Australian qualitative study of patient group practices to promote independence from pharmaceutical industry funders
}

\author{
Lisa Parker (D) ,' Quinn Grundy (D) , ${ }^{2}$ Alice Fabbri, ${ }^{1,3}$ Barbara Mintzes (D) ,' \\ Lisa Bero (iD 1,4
}

To cite: Parker L, Grundy Q, Fabbri A, et al. 'Lines in the sand': an Australian qualitative study of patient group practices to promote independence from pharmaceutical industry funders. BMJ Open 2021;11:e045140. doi:10.1136/ bmjopen-2020-045140

- Prepublication history and supplemental material for this paper is available online. To view these files, please visit the journal online (http://dx.doi. org/10.1136/bmjopen-2020045140).

Received 24 September 2020 Revised 14 December 2020 Accepted 18 January 2021

Check for updates

(C) Author(s) (or their employer(s)) 2021. Re-use permitted under CC BY-NC. No commercial re-use. See rights and permissions. Published by BMJ.

${ }^{1}$ Charles Perkins Centre and School of Pharmacy, Faculty of Medicine and Health, The University of Sydney, Sydney, New South Wales, Australia

${ }^{2}$ Lawrence S. Bloomberg Faculty of Nursing, University of Toronto, Toronto, Ontario, Canada

${ }^{3}$ Tobacco Control Research Group, Department for Health, University of Bath, Bath, UK

${ }^{4}$ Center for Bioethics and Humanities, University of Colorado Anschutz Medical Campus, Aurora, Colorado, USA

Correspondence to

Dr Lisa Parker;

lisa.parker@sydney.edu.au

\section{ABSTRACT}

Objectives To study how patient groups that accept pharmaceutical industry money perceive and manage the risk of undue influence from their sponsors.

Design Empirical ethics approach using a qualitative interview study.

Setting The Australian patient group sector.

Participants 27 participants from 23 patient groups, purposively recruited for diversity of group characteristics (degree of pharmaceutical industry funding, health focus, location) and participant role (staff, board members).

Analysis Interview data were transcribed and read repeatedly to identify concepts and patterns in the data. These were grouped into conceptual categories that described and explained the findings. We used an inductive analytical approach to identify important themes and concepts in the data.

Results Participants in this study described how the patient group sector receives pressure from pharmaceutical company funders to act in ways that prioritise company interests. Groups worked to try and protect their credibility and ability to act in ways of their own choosing using practical rules or 'lines in the sand' about industry funding activities. They were grouped around the dominant topics of: sponsor exclusivity, brand marketing, agenda setting, advocacy and content of group activities. Lines in the sand were largely experiencedriven and ethically informed; they varied between groups. There was also variable transparency among groups about financial interactions with pharmaceutical companies.

Conclusions It is important to know about patient group practices around pharmaceutical industry funders as this allows public scrutiny about the adequacy of such practices. Inadequate strategies may mean that funders can influence patient groups activities in ways that do not necessarily prioritise the interests of members. We found that groups differed in their approach, with little independent external guidance to inform responses to commonly encountered types of influence. Inadequate transparency limits the ability of the public to make informed assessments about the risk of bias over the activities of groups that accept industry funding.
Strengths and limitations of this study

- This interview study draws on comprehensive data from patient groups with diverse industry funding experiences, disease focus and jurisdiction.

- This is the first empirical study to focus on how patient groups manage risks to independence.

- The study was limited to the Australian setting.

- We spoke to staff and board members from patient groups but did not speak to individual patient advocates.

- Participants may have spoken selectively about their group's interactions with the pharmaceutical industry in a way that supported the concept of an independent patient group sector.

\section{INTRODUCTION}

Patient groups are important stakeholders in the health sector. Their roles include supporting patients, educating their members and health professionals, contributing to guideline development, funding medical research and advocating in relation to health services including affordable access to drugs. ${ }^{1-4}$ Patient groups commonly receive money from the pharmaceutical industry. For example, a Finnish study showed that $71 \%$ of 55 surveyed groups received pharmaceutical company money ${ }^{5}$ and a recent study of 104 wealthy US patient groups showed that $83 \%$ received funding from drug, device and biotechnology companies. $^{6}$

There is concern that acceptance of pharmaceutical industry money might compromise the independence of patient groups. ${ }^{7}$ This is important because a compromised patient group voice might end up furthering industry interests rather than those of their membership, for example, by selectively providing advice and lobbying for services and products that are also in sponsors' interests, and remaining silent on issues such as 
medication safety or high prices. In this paper, we draw on Jonathan Marks' analysis of public-private partnerships to explore financial interactions between patient groups and the pharmaceutical industry. ${ }^{8}$ We draw on his broad conception of independence, to mean patient group judgements, decisions, actions and beliefs that prioritise the interests of group members and the wider patient community, rather than the interests of commercial sponsors. While patient groups and the pharmaceutical industry may share interests in matters such as ready access to therapeutically useful drugs, there may be divergence between the interests of the two sectors in other important topics such as use of drugs that have poor side effect profiles, questionable therapeutic benefit and unreasonable cost. ${ }^{6910}$ Several studies have shown an association between industry funding and patient groups' positions on health and policy issues. ${ }^{11-15}$ For example, patient groups in the USA that advocated to maintain ready public access to opioids were more likely to be funded by opioid manufacturers than groups that advocated for restricted access. ${ }^{11}$ This is part of the increasingly recognised link between industry sponsorship of healthcare stakeholders and outcomes that favour the sponsor's interests, ${ }^{16}$ a pattern that is being repeated across clinical practice, ${ }^{1718}$ medical education, ${ }^{19} 20$ guideline development ${ }^{21}$ and medical research. ${ }^{22}$ There is urgency about identifying and managing financial conflicts of interests in the health sector in order to protect the public's interests, including their health.

Interactions between the pharmaceutical industry and patient groups may fall under the jurisdiction of selfregulatory codes of practice. Pharmaceutical trade associations around the world have codes of practice regulating member company relationships with the health sector, including with patient groups. ${ }^{23} 24$ These codes vary slightly depending on the jurisdiction-for example, codes in Europe, the UK and Australia require member companies to publicly disclose funding to patient groups, but this is not the case in the USA. ${ }^{25}$ Not all pharmaceutical companies are members of their local trade organisation and therefore not all companies are bound by these self-regulatory codes. In addition, umbrella organisations that provide support and resources to patient groups may have codes of practice that offer guidance on relationships with pharmaceutical company funders, often coauthored with the industry. ${ }^{26} 27$

There is a paucity of empirical research on how patient groups think about the possible impact of pharmaceutical industry sponsorship on their group's independence and how they act to protect their independence. Limited data suggest that at least some groups that accept pharmaceutical company money perceive a threat to their independence, ${ }^{528-31}$ and that some, but not all groups, adopt strategies such as transparency around funding, and formal conflict of interest polices. ${ }^{1}{ }^{28}{ }^{31-33}$ There is a lack of comprehensive, up-to-date information about other practices that patient groups may adopt to protect themselves against industry influence. We have previously written about the nature of patient group interactions with the pharmaceutical industry, describing a range of different attitudes and experiences articulated by people in patient group leadership roles. ${ }^{30}$ This paper sharpens our focus on the patient group-pharmaceutical company nexus, looking very particularly at the practical, day-to-day management of sponsor influence. This information is important for public scrutiny of current industry and group practices, and to allow groups to learn from each other when striving for best practice.

The impetus for the study was previously identified ethical concerns about pharmaceutical industry funding of patient groups. ${ }^{74}$ We undertook an empirical study to explore these concerns and to stimulate and inform conversations about how best to maintain patient group independence from the pharmaceutical industry into the future. Our research questions were:

- What are the views of people working in patient groups about the risk of harm to their independence from accepting pharmaceutical industry money?

- What practices and policies are currently in use by patient groups to mitigate these risks?

\section{METHODS}

\section{Design}

We adopted an empirical ethics approach, ${ }^{35}$ drawing on an emerging methodological discipline that combines empirical study with ethics theory to explore and comment on a matter of ethical importance. This approach assumes that empirical data and theoretical reflection can each inform the other to enable deep engagement with, and guidance for, a complex ethical topic. ${ }^{36}$ Using this approach, we designed an empirical study to identify what was happening in relation to our general topic of interest (pharmaceutical industry funding of patient groups). We used our knowledge of theoretical and applied ethics, drawing particularly on Marks' conceptions of independence and integrity ${ }^{8}$ to inform our research questions, specific lines of inquiry and analysis. Ultimately, we intended our findings about what is happening to inform our recommendations and contribute towards public discussion on the ethical question of what should be happening. For the empirical component of the work, we used qualitative research methods, which are well suited to exploring social ideas and behaviours such as perceptions about risk and practices around managing conflicts of interest. ${ }^{37} \mathrm{We}$ conducted individual interviews, with sampling, recruitment and data collection methods that were suited to our research questions. ${ }^{38-40}$

Our research team academic experts in industry influence in health (LB, QG, LP, AF and BM), health professionals (QG in nursing, and $\mathrm{LP}$ and $\mathrm{AF}$ in medicine), and experienced qualitative researchers ( $Q G$ and $\mathrm{LP}$ ). Our diverse experience and expertise enabled us to view and analyse the data from many different perspectives. We report our methods in keeping with the Consolidated criteria for Reporting Qualitative research guideline. ${ }^{41}$ 


\section{Participant population}

We conducted one-on-one interviews with key people working in patient groups who were familiar with their group's experiences and policies around funding and interactions with the pharmaceutical industry. We used the Australian patient group sector as a geographical case study for two reasons. First, we had access to information about pharmaceutical industry funding of patient groups, since Medicines Australia, the trade organisation for Australia's pharmaceutical industry, requires all its members to adhere to a Code of Conduct that states companies must publicly disclose their spending on patient groups. ${ }^{42}{ }^{43}$ Second, Australia has a wellestablished patient group sector, similar to that in other developed countries such as the UK, the USA, Canada and throughout Europe.$^{25}$ Some groups in Australia focus on specific health conditions and others focus more broadly on health service delivery for current or future patients ('health consumers') and their communities.

We constructed a non-exhaustive list of Australian patient groups using several sources. First, we extracted a list of the 230 Australian patient groups that had received pharmaceutical industry funding between 2013 and 2016, drawn from a database that our research group has previously created. This database collates the publicly available information about pharmaceutical company spending on patient groups, as required for all Medicines Australia members. ${ }^{42} 43$ The database is freely accessible at http://dx.doi.org/10.25910/5bc67fed51798 Second, we included all seven of the peak national and regional (state and territory) patient group organisations, which are focused on general health service matters. Third, we accessed the 53 patient groups listed as members on the website of the peak national patient group organisation, Consumers Health Forum (https://chf.org. au/our-members) on 15 November 2017 and searched for organisations not already identified through our other methods. This provided an additional 21 groups (running total 258). We also followed up suggestions from previous participants (snowball sampling) and searched via Google for groups linked to those previously identified (eg, groups with similar disease focus but serving different regions). When considering recruitment from those groups that did not appear on the database we checked for evidence of pharmaceutical industry funding on groups' websites (eg, pharmaceutical logos, sponsorship lists, annual financial reports).

\section{Sampling and recruitment}

We sampled purposively, aiming for participants with a range of experiences around industry funding. We reasoned that participant experiences were likely to be associated with overall levels of pharmaceutical company interest in contacting, funding and interacting with patient groups. We also considered that pharmaceutical interest, and therefore, participant experience might be associated with patient group focus, particularly in relation to specific diseases or pathological processes for which there may or may not be new products currently under patent, and the perceived reach or influence of the group (eg, local vs national jurisdiction.) Therefore, we sought to recruit participants from groups with differing characteristics across a range of variables such as: level of pharmaceutical industry funding, group focus (specific disease, general health service matters), jurisdiction (local, national). We also aimed to recruit from patient groups focusing on different types of disease and body system and different pathological processes (see online supplemental file 1). This was because we knew from clinical experience that new medications tended to coalesce around particular illnesses and/or pathophysiological processes. As such, we reasoned that some types of groups might be more likely than others to receive overtures from pharmaceutical companies with new drugs to market. We wanted to hear from groups representing current marketing opportunities for industry and also those that were not. We drew up a rough list of body systems and pathological processes (see online supplemental file 1) and tried to ensure that our final participant group included a reasonable spread across both lists. We also aimed to speak with participants holding experience interacting with pharmaceutical industry funders or developing and implementing organisational policy on pharmaceutical industry funding. As such we sought out both senior staff members and board members.

We began by targeting a few patient groups across a range of characteristics including disease/pathological process and funding status. Our first recruitment email went out to just four groups. As data collection proceeded, we focused on recruiting from patient groups with characteristics that we had not previously managed to recruit from and for participants with different roles. Our recruitment emails were sent directly to the Chief Executive Officers (CEOs) and/or Board Presidents if those contact details were publicly available, or if not, to the generic email address of our target patient groups.

We contacted 55 potential participants from 49 patient groups by email using details available in the public domain. Recruitment, data collection and analysis were conducted iteratively so that each could inform the other. Recruitment evolved as the study progressed to ensure diversity of participant characteristics and data.

\section{Data collection}

LP conducted semistructured interviews with participants, explaining her research interest in how health sector workers think about and manage industry influence, and professional experience as a medical clinician. She asked about participants' views and experiences with industry funding and how possible conflicts of interest were managed during their role in the current group (see online supplemental file 2). The interviews were conducted at a time and location suitable for the participant, face to face or over the phone. There was no observable difference in the quality of the data from phone interviews, ${ }^{44} 45$ and using this method enabled us 
to include participants from outside of the local area. All participants gave informed consent. The interviews were recorded, professionally transcribed and deidentified. Pseudonyms are used in this paper to protect participant confidentiality.

\section{Analysis}

Our analysis was informed by our prior reading of the literature on patient group interactions with the pharmaceutical industry and the theoretical concepts explored by Marks, particularly 'institutional independence'. We used widely practised qualitative research methods involving field notes, coding and writing memos about emerging topics of interest. ${ }^{37}$ LP wrote field notes after each interview that captured contextual information, initial impressions and reflexive thoughts. All transcripts and field notes were imported into NVivo software. LP read the field notes and early transcripts multiple times and developed an initial coding scheme generated from background knowledge on industry relationships with patient groups, theoretical ethics concepts and the emerging data. The coding scheme was used on selected transcripts (chosen for their conceptual interest and variety) by all members of the research team. Interpretations were compared at a team meeting and informed an updated coding scheme, which LP then applied to all transcripts (see online supplemental file 3). The team read and coded the same selected manuscripts from remaining interviews (again chosen for conceptual interest and variety) and exchanged ideas at fortnightly meetings. Selected codes were translated and expanded on by LP into memos that included theoretical reflection on ethical concepts. For example, in memos on independence we sought to compare and contrast how groups discussed and enacted limits to acceptable practice. Memos were cross-checked against the raw data to ensure accuracy of reporting and analytical interpretation.

\section{Patient and public involvement}

One member of the research team (BM) has had extensive involvement with women's health groups and consumer groups generally. She is a current member of Health Action International. We also coconvened a patient group stakeholder meeting in conjunction with one national and one state health consumer organisation in March 2020, to discuss and build on our research work. ${ }^{46} 47$

\section{RESULTS}

We sent 55 recruitment requests to individuals and generic email addresses associated with 50 different groups. Thirty-six were from industry-funded groups and 19 from groups without industry funding. LP interviewed 27 people (19 women, 8 men) from 23 groups, including $17 / 36(47.2 \%)$ people approached from industry funded groups and 10/19 (52.6\%) of people approached from groups without industry funding. The reasons for not interviewing 28 people included: non-response to recruiting email (19) or follow-up emails (4), refusal (4) and email-send failure (1). We had more recruiting success from individualised emails than from generic emails: $7 / 10(70 \%)$ emails to targeted staff members and $4 / 7(57 \%)$ targeted Board members resulted in interviews compared with 15/38 (39\%) generic patient group emails. Overall, two-thirds of participants were from industry funded groups, most of which were focused on specific health conditions, either with national or regional jurisdiction (see table 1 for details). The interviews were conducted between October 2017 and October 2018; they lasted 25-95 min (average $60 \mathrm{~min}$ ). We continued sampling until we were confident that we had spoken with a wide range of participants and were no longer hearing new information about patient group interactions with pharmaceutical industry funders. ${ }^{48}$

Participants talked about receiving pressure from the pharmaceutical industry to act in particular ways. They described strategies to maintain their independence, including paying attention to issues of: sponsor exclusivity, brand marketing, agenda setting, advocacy partnerships and content of patient group communications and events. We identified variation between patient groups in where they drew the line between acceptable and unacceptable practices relating to these topics. We also identified variation in patient group practices and policies around transparency of pharmaceutical industry sponsorship. We discuss all of these matters in more detail below.

\section{Undue influence from pharmaceutical industry sponsors}

Participants described how patient groups were pressured to act in ways that aligned with the interests of a pharmaceutical company funder. This meant that groups were not necessarily working towards their own, independently identified priorities. For example, one participant described how her group ended up producing and promoting an information pack at the request of a pharmaceutical company funder. Accepting money for this work meant being engaged in an industry-benefitting activity rather than pursuing the group's own prioritised goals. The job was seen by the participant as being incidental to her group's core mission and therefore resulting in opportunity costs, 'it ...just wasn't ... the best use of our time.' [Sally, CEO].

Groups also received pressure to act in ways that ran directly counter to their own interests. Participants described how company personnel sought to dictate the content of patient group communications and outputs. For example, one participant spoke about a company trying to control the content of an education seminar her group was running, and another recalled how a company representative had tried to stop a story in a patient group publication she was editing. Participants acknowledged that this kind of behaviour from funders could mean that groups were unable to provide people with independent support and advice, including being unable to inform 
Table 1 Characteristics of invitees, including participants and those invited that did not participate

Individuals interviewed $(\mathrm{n}=27)^{*}$ Individuals invited but not participating $(\mathrm{n}=\mathbf{2 8})$

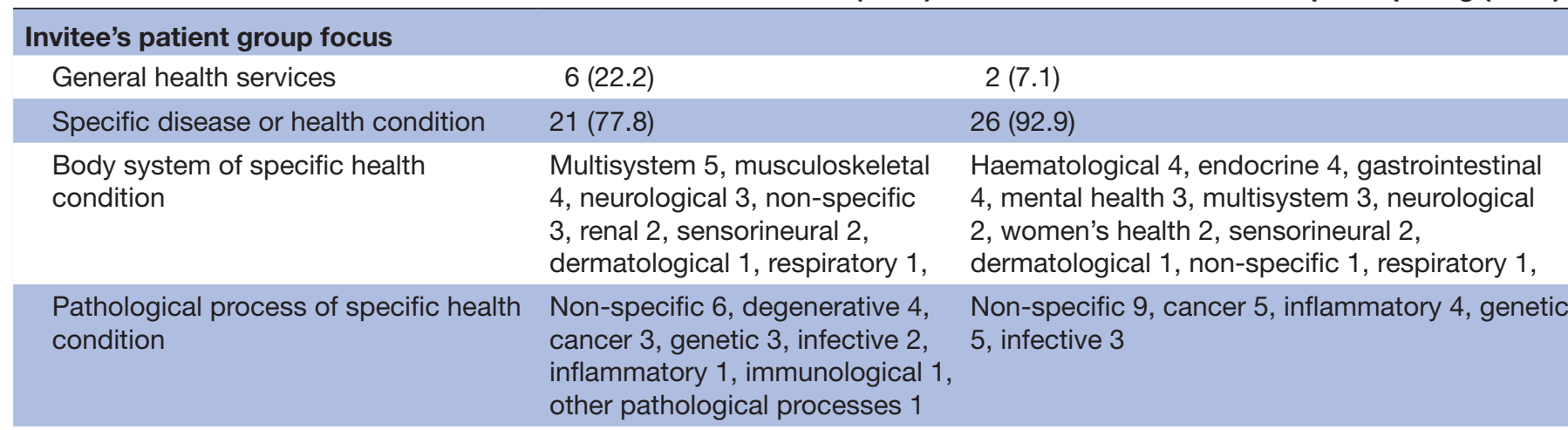

Invitee's patient group geographical jurisdiction

$\begin{array}{lrr}\text { National } & 15(55.6) & 19(67.8) \\ \text { Regional† } & 12(44.4) & 9(32.1)\end{array}$

Level of pharmaceutical industry funding (\$A)

Top quartile

$13(48.1)$

$15(53.6)$

(\$A103 $001^{* *}$ \$A4 107 981)†

Mid to lowest quartiles $4(14.8)$

$(\$ A<80-\$ A 103000) \ddagger$

No pharmaceutical industry funding§ $10(37.0) \quad 9(32.1)$

\begin{tabular}{lrl} 
Participant role in group & \\
Staff-CEO (including acting) & $19(70.4)$ & NA \\
Staff, otherף & $4(14.8)$ & NA \\
Board member & $4(14.8)$ & NA \\
\hline
\end{tabular}

Values are numbers (percentages) unless stated otherwise. ${ }^{30}$

*The four groups from which two participants were interviewed had the following characteristics: (1): general consumer health focus, regional group, no pharmaceutical industry funding; $(2,3)$ : disease-specific focus, national group, top-quartile pharmaceutical industry funding; (4) disease specific focus, regional group, mid-quartile funding.

†Regional groups are based in specific Australian states or territories and serve members living within those regions; most are affiliated with a national group with the same health focus but have separate funding sources.

‡Group's position in list of patient groups that received money from the pharmaceutical industry, as listed in our database of funding disclosed by Medicines Australia members during the years 2013-2016 inclusive.

$\S$ Not listed on our database of disclosed pharmaceutical funding of consumer health groups and no obvious declaration of pharmaceutical funding on group website.

IResearch manager, secretary, fundraising manager.

${ }^{\star *} £ 54$ 300; €63 600‡£54 300; €63 600.

CEO, Chief Executive Officer; NA, not applicable.

patients about medications that were not manufactured by their pharmaceutical funders.

Some participants were aware of the power dynamics of the sponsor relationship, describing how budgetary pressures meant it was hard to refuse industry money even if it meant acting in ways they might not have otherwise chosen. In contrast, other participants did not perceive themselves or their group to be at risk of undue influence from pharmaceutical funders because, they reasoned, their group's actions could not be of any commercial benefit to the company. For example, participants stated they could not further company interests because they did not perceive their group as having any power to influence drug prescribing or much influence over the government's drug subsidy scheme.
Similarly, many participants had no concerns about promoting industry-funded research, because they felt that this was about science without any elements of industry marketing. For example, Denise (board member) said she saw no issue with accepting money from a company to fund 'a particular doctor to go to [her group's conference] and talk about the results of the [company-funded] trial that was close to being finished ... Because, I mean, the results of the trial are the result, you know, like, it's a scientific presentation, it's not a marketing presentation.' There was no perception that discussion of industryfunded science research could be used by a company as a marketing exercise.

Regardless of their views on the risk of undue influence from pharmaceutical company sponsors, most 

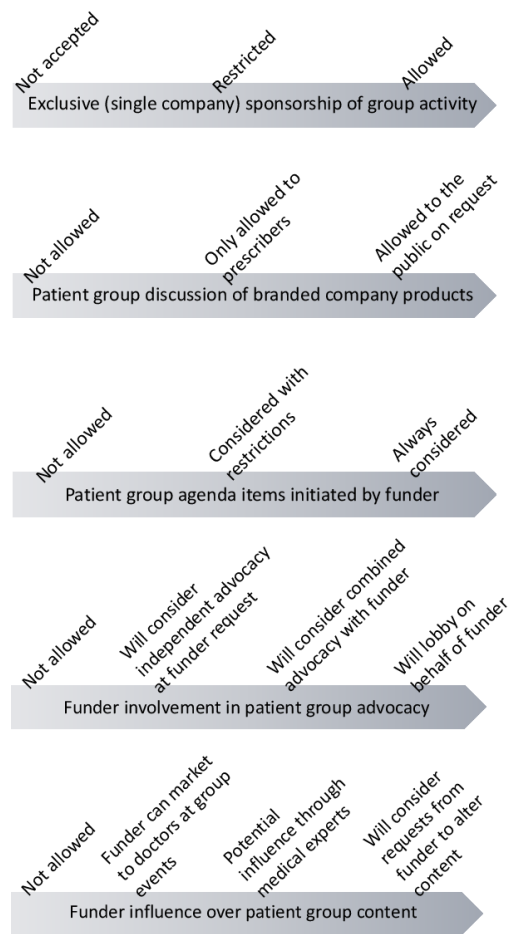

Figure 1 Patient group practices to protect against undue influence from pharmaceutical industry sponsors: dominant themes and variation in practice.

participants felt that accepting pharmaceutical industry money carried some risk of damage to the public's perception of their group. They were worried that the public might assume their group was working for the benefit of sponsors, rather than as an independent body engaging in support, education and activism for the benefit of patients and carers. Participants took the risk of reputational damage very seriously and always considered this when making decisions about accepting pharmaceutical company money. As Alan (CEO) said, 'If we take funding (we think about), 'Does it compromise our credibility?' We guard that very jealously... our credibility is probably our most important asset.'

\section{Patient group independence}

All participants talked about the importance to their group of being independent from the pharmaceutical industry. For participants, being independent meant the group having total control over their own activities and priorities and not letting funding bodies dictate action or set preferences. For example, Fiona (CEO) spoke about making sure her group was 'driv[ing] the agenda' rather than being 'driven by the corporate action.' Many participants also spoke about independence in terms of receiving (or at least being open to receiving) funding from multiple sources, explaining that if their group was willing to accept money from more than one funder then it clearly could not be a mouthpiece for any single sponsor. This explanation was also given to members of the public and pharmaceutical companies that accused a patient group of being 'in the pockets' of one (competitor) company: 'We contact every single pharmaceutical company ... I want to be very clear ... that everyone has an equal opportunity to partner with us and if they choose not to, that is their own choice.' (Lyn, CEO)

\section{'Lines in the sand' that define limits of acceptable practice}

Participants talked about groups preserving their independence by having careful processes around funding decisions and incorporating specific rules that defined the limits of acceptable behaviour. Decisions about funding, including pharmaceutical industry sponsorship, were generally made by group Boards and the CEO. Some groups had formal policies about working with industry that helped to guide decision-making processes. This aimed to promote consistency in outcomes and helped CEOs to act in line with their Boards without necessarily having to take each decision back for wider discussion. Other participants described less formal decision-making processes through group discussions on a case by case basis. Policies and informal decisionmaking processes were informed by a range of sources, most prominently two industry-affiliated resources (the industry trade organisation's Code of Practice ${ }^{49}$ and a document cobadged by industry and a national health consumer body ${ }^{26}$ but also one or more of personal philosophies of key staff entrenched in the organisational culture and member views about pharmaceutical industry interactions.

Many participants, both with and without formal policies, alluded to informal rules or 'lines in the sand' (Paula, CEO) that defined the group's acceptable decisions and practices on industry funding. Together they represent prominent ethical issues for industry funding around which patient group practices and concerns coalesce. Participants talked about these rules as defining limits of ethical practice, beyond which their group would not step. As such these rules constituted guidance for ethical decision making. They were not necessarily straightforward: for example, although the lines were generally presented as rigid, as in 'we will do x but not y', participants also described legitimate circumstances whereby y would be acceptable. We identified five dominant topics representing such 'lines in the sand' These were sponsor exclusivity, branded product marketing, agenda setting, advocacy and content of group activities. No participants discussed all five, but most explicitly or implicitly described one or more. We searched for, but did not find, any clear patterns between participant roles or organisational characteristics and their comments on each topic. Within each theme, we identified several places where different groups drew their line, such that some groups adopted a wider set of acceptable practice than others (see figure 1 and table 2). Box 1 provides an illustrative case study with additional case studies available in online supplemental file 4 . 
Table 2 Patient group practices to protect against undue influence from pharmaceutical industry sponsors: dominant themes and variation in practice

Patient group practices $\quad$ Example quotes from participants

\section{Sponsor exclusivity}

Will not accept exclusive (single company) sponsorship

Has restrictions on accepting exclusive (single company) sponsorship, for example, only for small projects and/or clear fee for service

Will accept exclusive (single company) sponsorship without restriction

\section{Brand-marketing}

Will not mention branded products

Will not mention branded products to the public; will allow company ads for branded products in patient group magazine aimed at primary care practitioners

Will mention branded products to the public on request

\section{Agenda setting}

Will not accept funder-initiated projects with restrictions

Will always accept and consider funder-initiated ideas

\section{Funder involvement in patient group advocacy}

Will not allow funder to influence group's advocacy

\section{May act independently on industry prompts about advocacy}

May cobadge advocacy submissions to government or media with industry funder
'Why would you just work with one company? That's giving out all the wrong messages.' Felicity, CEO

'I've got a [big] meeting coming up soon and a couple of companies wanted exclusively me to go to them [for registration and travel funding] and I said, 'No, I feel uncomfortable' ... It's better if it's funding from all of them rather than just one ... There's one company that's offered me to go [on] another [short] trip ... I accepted that flight because they want me to do a presentation there ... otherwise normally no.' Emily, CEO

'Now we really have maybe one or two serious [Pharma] companies only... at the moment it's only one actually.' Neil, CEO

'When you're talking about any particular drug effect you talk about the generic not the brand.' Irene, CEO

'We have a policy of not promoting specific brands. We don't promote any products. We have a policy if patients come to us, asking about products, we never actually give advice. We only give advice about general factors or lifestyle ... We do accept in our GP magazines, the advertisement from some companies about their products, but that comes without any endorsement from [our group] and it comes directly from the company so this is fairly transparent.' Neil, CEO

'We don't mention the brand names in any of our written material [but] people call us and say, 'Oh, what product is that?' And we'll say, 'Well, there's (Branded Product 1), there's also this, there's also that.' So we do-we try to help people without pushing a particular line.' Ian, CEO

'Pharmaceutical funding is a bit of a last resort so we use it where we can't get money to do things that have already been strategically planned out. So if pharma comes to us and says, hey how about this project, that doesn't happen.' Gina, Board member

'I'm also open to pharmaceutical companies coming to me with ideas ... but l'm only interested in partnerships with Pharma if we're there from the outset and if we are the ones who are managing the project.' Robyn, CEO

'Sometimes [the projects are] initiated by us... and in some cases it's them contacting us about a specific initiative that ... they've got underway and want us to be involved in.' Lyn, CEO

'You can't have a situation where Acme Pharmaceuticals is paying [their Public Relations people] to write [your] media release... that just gets you into trouble ... where someone is drafting a press release for you, then you just get herded.' Chris, Board member

'If a company approaches us that they've got a new drug coming up for the Consumer Commission [drug regulator] then we leak it out to our consumers on the day, 'this is what it is, this is what it does, here's some information about it, if you'd like to make a submission, you know, please do' ... And if we think it's a good thing we do a very brief submission ourselves.' Irene, CEO

'Sometimes a Pharma and if we've got a good relationship with them and they're not-say for example recently one of the [disease a] drugs got PBS listing [author note: government subsidy through the Pharmaceutical Benefits Scheme] and we were happy to be quoted to say like, the incidence of [disease a] is blah-blah-blah, but not endorsing their drug so, that was fine.' Irene, CEO 
Table 2 Continued

Patient group practices

(Reported about others) Funder directly shapes

the group's advocacy agenda

\section{Example quotes from participants}

'I do know that some health consumer organisations in the past and now, are funded by pharmaceutical companies and then lobby for medications to be listed on the PBS [for government subsidy]. We've never done that, never.' Robyn, CEO

\section{Funder influence over content of patient group activities}

Will not allow funder input into content

'We're very deliberate in having an independent editorial with our [patient group] magazine. So Pharma do fund a little bit of that, money goes towards our [magazine] editorial but we make sure that there is no, they don't sit in any of our editorial committees, they don't get a say in what we do or print.' Kevin, Board member

Will not allow funder input into content of formal educational event; companies can fund and market products to health professionals at educational fringe

'We offer sponsorship packages [to the pharmaceutical companies for educational events] ... There's two different days that we do, one is for allied health professionals and one is for GPs. The allied health professionals, the pharma companies aren't that interested in because they don't have prescription pads, and the GP seminar days are the one that they have much more interest in ... They come on the day, have a stand, have their information.' Sally, CEO

Potential for funder influence over content through 'We have ... scrutiny from our medical scientific committee, which is, as medical experts who may themselves accept industry money I said, 12 people who represent different specialities... they all declare their conflicts of interest' Neil, CEO

Will consider requests from funder to alter content 'We've got [a new booklet] at the moment that we're working on, we developed that in collaboration with some health consumers, the health professionals, the health educators ... When we're absolutely happy with it I [will] give it to the [pharmaceutical industry] partner to look at and they will, if they come back with any suggestions they understand that it is at the discretion of [our patient group] if we accept what their suggestions might be.' Robyn, CEO

CEO, Chief Executive Officer; GPs, General Practitioners.

\section{Risks and benefits of accepting industry funding}

The participant cohort included people affiliated with groups that did not accept pharmaceutical industry money. These participants considered that any industry funding would present a risk to their independence. For example, Helen (CEO) explained that this might mean the group would have to act in ways that the company dictated:

'The minute you introduce Big Pharma or any of the other big multinational players, there is a threat to your independence or on your ability to take a particular position because you may have to sing or dance to their tune.'

As such, in order to remove the risk of influence these groups refused any pharmaceutical company money.

For others, industry funding was not necessarily their preferred option, but a pragmatic solution to budgetary pressures. For example, Alan (CEO) alluded to the risks of associated with industry funders, but was willing to accept the money anyway since it was so hard to find alternative funding sources: 'In an ideal world you'd say we'll fund all this stuff without having any reference to [pharmaceutical industry] funders, but we don't work in an ideal world ... Funding is ... difficult to get.' Funding pressure was a particular issue for groups focused on lesser-known diseases where other sources of income, such as philanthropy, government or public donations, were more difficult to obtain. As Emily (CEO) explained, 'it's very competitive out there. I mean it's, for a small organisation like us, and people haven't heard of the disease before and they don't care unless it affects them, why would they worry? You know? It doesn't affect them.' For many participants, the limited funding options available to patient groups meant they felt they had to accept the inherent risks associated with pharmaceutical industry sponsorship in order to stay solvent.

\section{Transparency}

Transparency was described by participants as being an important element of independence, particularly perceived independence. Participants said that being open to members about where money was coming from was a necessary practice and the right thing to do. Dominant reasoning here was that the group should to give due credit to their sponsors and that groups should protect their integrity by being up front about accepting money from companies. None of the participants talked about transparency around funding in the context of assisting members or the public to assess any possible bias from funder influence. We did not discern any particular patterns among the patient group characteristics (funding status, disease/pathological process, geographic 
Box 1 Case study illustrating practices for working with pharmaceutical industry sponsors

Disease-specific patient group, high level of funding from pharmaceutical industry, no formal policy (Irene, CEO)

The patient group that Irene works for has 'quite longstanding relationships with many of the pharmaceutical companies built up over a number of years' particularly 'to develop patient or primary care resources' such as primary care workshops for general practitioners and nurses. The group does not have a formal policy about working with industry. Sponsor exclusivity: The larger educational events tend to be funded by multiple companies, 'so if it's a big event... we combine together so if it's going to be a $\$ A 70000$ project then, we might need two or three of them to come together.' However, the group does allow companies to have exclusive sponsorship if they wish, 'we got a big grant from one company for [a new project] so it all depends what they're interested in and how excited they get about a project.'

Brand marketing: Irene's group allows sponsoring companies to display 'their logo on a [patient group] document' and at the beginning of funded educational events but the speakers don't mention branded products: 'We recognise [funders] at the beginning saying 'this has been supported by whoever' but ... we know the rules, we don't talk about their drug, it's more the class of the drug. If we're talking about benefits of a particular drug, we never say the drug that the pharma company makes. It's all very above board and done properly.'

Agenda setting: Irene's group takes pharmaceutical company interests into account when deciding on their agenda: 'We try and make [our events] educationally based because that's the sort of thing that [companies are] interested in because obviously it reaches both health professionals and consumers which is probably what [companies] would be interested in.' The group is also willing to discuss pharmaceutical company ideas for particular activities.

Advocacy: The group will consider company requests for joint advocacy. They were happy to be quoted on a company's media release about a drug that had just received government subsidy noting that 'it was something that was out there in the market already, it was a good thing.' They are also happy to pass information on to their members from pharmaceutical companies that had new drugs coming up for government review for approval or subsidy, and encourage members to make supporting submissions. They did not, however, agree to a recent company request for them to endorse a 'new drug that's only in phase two trials at the moment... [because] it was just too much, it didn't sit right.'

Content: Pharmaceutical companies have no influence over the content of the educational events, which are run by medical specialists, often without any patient group personnel attendance.

jurisdiction) and whether the organisation had transparency policies or practices in place.

The form and extent of described transparency practices was highly variable (see box 2 ). For example, only some participants said that their groups actively informed members about financial interactions with the pharmaceutical industry. Other participants explained that their group relied on companies to declare their spending on patient groups, talking about the industry trade organisation's Code of Practice, which stated that member companies must publicly disclose their donations to patient groups. ${ }^{49}$ None of these participants talked about the limitations around these declarations or the lack of
Box 2 Varying transparency practices adopted by patient groups around pharmaceutical industry funding

- Annual reports: The patient group's annual report includes information on pharmaceutical industry sponsors, including one or more of: funder name, amount of money, use of money; the annual report may or may not be publicly available to non-members

- Annual personal declarations: The group's personnel (eg, Board members, expert medical advisors) are required to make annual declarations about personal receipt of pharmaceutical industry funds, including one or more of: funder name, amount of money, what services or activities the money was paid for; this information may or may not be publicly available to non-members.

- Timely declarations: Receipt of pharmaceutical company funding by group or group personnel is declared at the time of activity or decision making, for example, at industry sponsored educational events, on industry sponsored information booklets, at committee meetings of staff and expert medical advisors.

- Public policy: The patient group's policy around working with pharmaceutical company funders is available on the group's website; this may or may not be publicly available to non-members.

- Accessibility: The policy and sponsorship details are highly visible, and readily available, within few 'clicks' on the website, including to non-members.

- No transparency detail: Group does not provide any detail about industry sponsors beyond company names or logos.

transparency around sponsorship from non-member companies.

Some of the more limited forms of transparency that participants talked about meant that it was unlikely group members, let alone the general public, would know about the links between the group and pharmaceutical companies. Some participants acknowledged this: for example, Sally (CEO) stated that her patient group members 'probably aren't aware that we're connected to [pharmaceutical companies].' However these participants generally felt that their members would be in favour of them accepting pharmaceutical industry money, so inadequate transparency practices did not trouble them unduly.

A minority of participants discussed the tension between transparency and promotion, realising that their group's public declaration of company funding could deliver promotional marketing for the company. For some, this was deliberate. For example, Tegan (CEO) explicitly promised wide exposure to her pharmaceutical sponsors, 'I say that we will put your logo on our programs and on our Facebook page and on our Instagram and our Powerpoint slides on the day, just to let them know that we'll be publicising their company as being a sponsor.' Others were concerned that naming of sponsors might be seen by the public as patient group endorsement of company products. That is, while it was widely seen as important to acknowledge industry funding, some participants recognised that this might be perceived as a stamp of approval for the funding company and their relevant products, although that was not the intended message from the patient group. 
Transparency within the company was also discussed by participants. Patient group Board and expert committee meetings typically began with a request for attendees to declare any conflicts of interest. It was common for individuals to declare involvement in research and abstain from any related decisions (eg, around patient group funds being used for that research), but no participant could recall ever hearing Board members or experts declare receipt of pharmaceutical company money as a financial conflict of interest when discussing patient group agenda setting or other activities. That is, while it was usual practice for groups to be upfront about receiving company money, either through their own or the funding company's transparency declarations, it was not front of mind to consider that colleagues or the public would want to know about industry sponsorship of key individuals within the patient group.

\section{DISCUSSION}

\section{Statement of principal findings}

Participants in this study described how the patient group sector receives pressure from pharmaceutical company funders to act in ways that prioritise company interests over their group's interests. This places patient groups that accept industry money at risk of losing their independent voice. Participants were variably aware of this risk but acutely aware of public perception of perceived influence. They described how groups worked to try and protect their public credibility and their ability to act in ways of their own choosing rather than to meet the needs of their sponsor. Many industries, including the pharmaceutical industry, use a Code of Conduct approach to outline their expectations for ethical behaviour among their members. Using the insights from the discipline of applied ethics in this way we identified participants' views on the limits of ethically acceptable behaviour. We found that there were some dominant ethical topics that participants talked about but there was little consensus around what constituted an acceptable behaviour limit or 'line in the sand'. Some practices fell short of what others would regard as necessary safeguards, suggesting that groups using more lax restrictions were vulnerable to the very real threat of industry influence. Participants also described how the patient group sector saw transparency about financial interactions between patient groups and pharmaceutical companies as important but not necessarily for the reasons discussed in the healthcare literature on commercial influence in health. Transparency was seemingly more about giving due credit to sponsors than about alerting the public to risk of bias or prompting disengagement from industry. Ways of declaring industry funding were variable, sometimes inadequate. In particular, there was an over-reliance on industry declarations, which may be hard to find, lacking detail or absent altogether. There was limited recognition of the importance of transparency around industry funding of key individuals within or advising patient groups. Such practices mean that the public are unable to make informed assessments about the risk of bias over the activities of groups that accept industry funding.

\section{Strengths and limitations of the study}

Ours is the first Australian study we are aware of that identifies the broad range of day-to-day practices that patient groups actually use to mitigate against undue actual or perceived influence from pharmaceutical industry funders. It builds on other studies that provide information on practices in different countries. ${ }^{528}$ This information is important because it allows public scrutiny and enables identification of best practice. This study was limited to the Australian setting; groups in other jurisdictions may have different levels of regulation or guidance. Nevertheless, the results are likely to have global relevance since there is international evidence that many patient groups accept pharmaceutical industry funding. ${ }^{5} 153150$ Although we spoke with diverse participants affiliated with a range of groups we did not cover all types of patient groups and did not speak with individual patient advocates unaffiliated with a patient group so we may have missed some issues or ideas. In addition, given that those we did interview held senior positions, the participants may have been experienced in managing the expectations of the public (including interested researchers) about their group's relationships and interactions with industry, and delivered information that supported the concept of an independent patient group sector. However, participants appeared to speak candidly about their experiences and views and we did hear a range of perspectives about the industry, including positive, negative and unsure, as described in our previous paper from this study. ${ }^{30}$

\section{Correlation with existing literature}

Our finding that some patient group personnel experience pressure from pharmaceutical industry funders correlates with results from other studies. ${ }^{52} 3050$ This suggests that at least some companies use money to seek influence over patient groups in ways that prioritise commercial over patient group interests. It means the sector is vulnerable to the kind of high level dependence that Marks describes, whereby industry funding generates overt or subtle reciprocities from patient groups. ${ }^{8}$ Many industries, including the pharmaceutical industry, use a Code of Conduct approach to outline their expectations for ethical behaviour among their members. Using the insights from the discipline of applied ethics in this way, we describe participants' views on the limits of ethically acceptable behaviour. We found that there were some dominant ethical topics that participants talked about but there was little consensus around what constituted acceptable behaviour limits or 'lines in the sand'.

The concept of 'lines in the sand' describes the kinds of rules that patient groups are using to navigate the challenges of industry funding. The lack of a consistent, independent approach is concerning for the sector. Some patient group personnel feel immune to undue influence 
from pharmaceutical industry funders, in the same way that health professionals regard themselves as withstanding industry influence. Evidence suggests, however, that people can be unconsciously influenced by even small amounts of money. For example, gifts from pharmaceutical companies can influence clinician prescribing, ${ }^{51} 52$ and drug and device industry funded research is more likely to deliver outcomes that are favourable to the sponsor than research funded by other sources. ${ }^{22}$ Patient groups that feel immune to influence because of a perceived lack of power as non-prescribers echo the views of non-prescribing nurses. However, nurses are important marketing targets for pharmaceutical companies because of their extensive impact over treatment and purchasing decisions in hospitals, ${ }^{53}$ and similarly patient groups can be useful to companies because of their impact on drug use through disease awareness, research and drug advocacy.

Previous studies on how patient groups manage conflicts of interest around pharmaceutical funders have concentrated mainly on transparency around funding and policy. These show that some, but not all, patient groups disclose industry funding ${ }^{691432} 33$ and a minority have publicly available conflict of interest policies. ${ }^{6}{ }^{32}$ Our results corroborate these studies and we also provide detailed information on practices used by some patient groups to reduce the risk of undue influence from pharmaceutical sponsors.

\section{Implications for policy and practice}

Much of the literature around patient group interactions with the pharmaceutical industry discusses the importance of codes of practice authored by industry and/or patient groups, to guide and manage financial relationships. Highlighted issues often include rules around agenda setting, funding diversity and transparency. Our work shows that patient groups are listening to this advice, and many are adopting particular practices around these topics. However, our work also suggests that rules might not always be sufficient protection against the risk of industry influence, since some groups are adopting practices that others are likely to consider inadequate. In addition, promoting a rule-based 'solution' for patient group-industry interactions presupposes that any perceived 'problem' with industry funding in the patient group sector stems from inadequate guidance or regulation. Other ways to frame the problem (and subsequently address the solution) are largely ignored but could include: lack of separation of powers within patient groups (fundraiser, advocate, educator) and lack of alternative funding sources.

Separation of powers has been championed by Rose ${ }^{34}$ and Marks ${ }^{8}$ who each advocate for maintaining strict separation within patient groups between fundraisers and those who set the agenda, write communications and drive policy. They argue that personnel who build strong relationships with industry funders are more likely to feel the social pressure of reciprocity and may be more favourably predisposed towards company policies and practices. Separating fundraising duties from patient group executive duties may help to ameliorate this possibility. Ideally, groups would also separate out governance duties to a different committee who would monitor practices and evaluate outcomes around pharmaceutical company interactions. ${ }^{54}$ These ideas challenge the traditional setup of patient groups, whereby Board members and the CEO tend to be responsible for building and reviewing funder relationships and writing group agendas and policies, and separate governance committees are non-existent. Rose herself acknowledges that paucity of funds and staff in many smaller patient groups will make her recommendations difficult to put into practice, but they remain an important conceptual standard.

Another way of separating policy-makers from interactions with pharmaceutical industry personnel could be to enforce a shared corporate pool of funds ${ }^{9}$ via a tax on industry profits or based on a percentage of marketing spending. ${ }^{55}$ This, however, would not address the underlying issue of agenda distortion that might arise from the patient group sector relying on a commercial industry with a particular set of priorities around drugs and drug policies. ${ }^{80}$ That is, even if a group has separation of powers as a way to protect against undue influence from pharmaceutical industry funders, they might still be cognisant of prioritising activities and advocacy that appeal to future industry funders (eg, focus on educating health professionals rather than patients, or on long-term structural change) and neglect those that run directly counter to future industry funders (eg, drug safety, preventing overdiagnosis and overtreatment). ${ }^{54}$

Participants described varying approaches to practices with a clear potential for undue influence, such as sponsor involvement in shaping advocacy, information materials and educational content. This was despite Australia's industry Code of Practice ${ }^{249}$ and the joint guidance from industry and a health consumer group. ${ }^{26}$ This may reflect the guidance document focus on general principles rather than practical suggestions, and industry involvement in developing codes.

An alternative is complete disengagement from the pharmaceutical industry. ${ }^{7}$ This would entail recognition of the inadequacy of alternative funding sources, and require increased support from other potential funders such as governments, with an understanding that patient support and a patient voice are important components of national healthcare services. Disengagement from the industry would build more public surety about patient group sector priorities being patient issues rather than commercial interests.

\section{Unanswered questions and future research}

We do not know the best way for patient groups to remove the risk of pharmaceutical industry influence but still receive company money, or if this is even possible. Some groups have taken the bold step of complete independence from pharmaceutical industry funding. 
Even so, there may be residual industry influence in the sector if groups whose interests naturally align with pharmaceutical companies are preferentially funded and empowered.$^{30}$ Future developments should not be led by pharmaceutical industry sponsors alone. We recently worked with peak bodies to convene a stakeholder meeting of patient groups to discuss the risks and benefits of accepting pharmaceutical funding, and to share ideas and resources about how best to proceed into the future. ${ }^{46} 47$ This meeting was a step towards addressing the need for independent, sector-wide guidance with resources that support and inform patient group policies and practices to mitigate against pharmaceutical industry funder influence.

\section{CONCLUSIONS}

Information about how patient groups protect themselves against undue influence from pharmaceutical industry funders is important because it allows public scrutiny and conversation about the adequacy of such practices. There is insufficient empirical research around which practices are most effective. Inadequate strategies may mean that pharmaceutical funders are influencing patient group activities in ways that do not necessarily prioritise the interests of group members or the wider public. Transparency around patient group acceptance of pharmaceutical industry money remains patchy, hampering the public's knowledge about possible links between industry sponsorship and patient group activity. Industry influence over all the key stakeholders in healthcare should be explored and contained in order to maintain a health sector that prioritises the public's health.

\section{Twitter Quinn Grundy @QuinnGrundy}

Acknowledgements We thank all the individuals who took time to participate in our interviews. We also thank E Karanges and S Swandari for their contributions towards building the database of industry payments to patient groups.

Contributors LP designed the study, collected the data, participated in the analysis and wrote the first and subsequent drafts of the manuscript. AF, QG, BM and LB participated in the design, data analysis and commented on all drafts, including reading and approving the final manuscript. The corresponding author attests that all listed authors meet authorship criteria and that no others meeting the criteria have been omitted. LP is the guarantor.

Funding No specific funding was received for this study. QG was supported by a postdoctoral fellowship from the Canadian Institutes of Health Research. AF was supported as a post-doctoral fellow by the National Health and Medical Research Council of Australia (NHMRC), project grant no.1122332.

Competing interests All authors have completed the ICMJE uniform disclosure form at www.icmje.org/coi_disclosure.pdf and declare: no support from any organisation for the submitted work; no financial relationships with any organisations that might have an interest in the submitted work in the previous three years. BM is a member of the European network of Health Action International (HAl-Europe). All other authors declare no other relationships or activities that could appear to have influenced the submitted work.

Patient consent for publication Not required.

Ethics approval The study was approved by The University of Sydney Human Research Ethics Committee (project number 2017/758).

Provenance and peer review Not commissioned; externally peer reviewed.

Data availability statement Data are available in a public, open access repository. The database of publicly declared industry payments to patient groups is available at: https://researchdata.ands.org.au/pharmaceutical-industry-funding-december2016/1330638https://researchdata.ands.org.au/pharmaceutical-industry-fundingdecember-2016/1330638.

Supplemental material This content has been supplied by the author(s). It has not been vetted by BMJ Publishing Group Limited (BMJ) and may not have been peer-reviewed. Any opinions or recommendations discussed are solely those of the author(s) and are not endorsed by BMJ. BMJ disclaims all liability and responsibility arising from any reliance placed on the content. Where the content includes any translated material, BMJ does not warrant the accuracy and reliability of the translations (including but not limited to local regulations, clinical guidelines, terminology, drug names and drug dosages), and is not responsible for any error and/or omissions arising from translation and adaptation or otherwise.

Open access This is an open access article distributed in accordance with the Creative Commons Attribution Non Commercial (CC BY-NC 4.0) license, which permits others to distribute, remix, adapt, build upon this work non-commercially, and license their derivative works on different terms, provided the original work is properly cited, appropriate credit is given, any changes made indicated, and the use is non-commercial. See: http://creativecommons.org/licenses/by-nc/4.0/.

\section{ORCID iDs}

Lisa Parker http://orcid.org/0000-0001-8635-6953

Quinn Grundy http://orcid.org/0000-0002-7640-8614

Barbara Mintzes http://orcid.org/0000-0002-8671-915X

Lisa Bero http://orcid.org/0000-0003-1893-6651

\section{REFERENCES}

1 Baggott R, Jones $\mathrm{K}$. The voluntary sector and health policy: the role of national level health consumer and patients' organisations in the UK. Soc Sci Med 2014;123:202-9.

2 Baggott R, Forster R. Health consumer and patients' organizations in Europe: towards a comparative analysis. Health Expect 2008;11:85-94

3 Mandeville KL, Barker R, Packham A, et al. Financial interests of patient organisations contributing to technology assessment at England's National Institute for health and care excellence: policy review. BMJ 2019;364:k5300.

4 Rothman SM, Raveis VH, Friedman A, et al. Health advocacy organizations and the pharmaceutical industry: an analysis of disclosure practices. Am J Public Health 2011;101:602-9.

5 Hemminki E, Toiviainen HK, Vuorenkoski L. Co-Operation between patient organisations and the drug industry in Finland. Soc Sci Med 2010;70:1171-5.

6 McCoy MS, Carniol M, Chockley K, et al. Conflicts of interest for Patient-Advocacy organizations. N Engl J Med 2017;376:880-5.

7 Moynihan R, Bero L. Toward a healthier patient voice: more independence, less industry funding. JAMA Intern Med 2017;177:350-1.

8 Marks J. Chapter 7: in praise of separation. The perils of partnership: industry influence, institutional integrity, and public health. New York: Oxford University Press, 2019: 103-21.

9 Ozieranski P, Rickard E, Mulinari S. Exposing drug industry funding of UK patient organisations. BMJ 2019;365:I1806.

10 Batt S. Who will support independent patient groups? BMJ 2014;349:g6306.

11 Lin DH, Lucas E, Murimi IB, et al. Financial conflicts of interest and the centers for disease control and prevention's 2016 guideline for prescribing opioids for chronic pain. JAMA Intern Med 2017;177:427-8.

12 Public Citizen. Patients' groups and Big Pharma 2016, 2020. Available: http://www.citizen.org

13 Jørgensen KJ, Gøtzsche PC. Presentation on websites of possible benefits and harms from screening for breast cancer: cross sectional study. BMJ 2004;328:148.

14 Perehudoff SK, Alves TL. The patient \& consumer voice and pharmaceutical industry sponsorship. Amsterdam: Health Action International, 2011.

15 Fabbri A, Parker L, Colombo C, et al. Industry funding of patient and health consumer organisations: systematic review with metaanalysis. BMJ 2020;368:16925.

16 Institute of Medicine. Conflict of interest in medical research, education and practice. Washington, DC: The National Academies Press, 2009.

17 Rhee TG, Ross JS. Association between industry payments to physicians and Gabapentinoid prescribing. JAMA Intern Med 2019;179:1425-8. 
18 Khan R, Nugent CM, Scaffidi MA, et al. Association of biologic prescribing for inflammatory bowel disease with industry payments to physicians. JAMA Intern Med 2019;179:1424-5.

19 Moynihan R. Doctors' education: the invisible influence of drug company sponsorship. BMJ 2008;336:416-7.

20 Spurling GK, Mansfield PR, Montgomery BD, et al. Information from pharmaceutical companies and the quality, quantity, and cost of physicians' prescribing: a systematic review. PLoS Med 2010;7:e1000352.

21 Norris SL, Holmer HK, Ogden LA, et al. Conflict of interest in clinical practice Guideline development: a systematic review. PLoS One 2011;6:e25153.

22 Lundh A, Lexchin J, Mintzes B, et al. Industry sponsorship and research outcome. Cochrane Database Syst Rev 2017;2:MR000033.

23 European Federation of Pharmaceutical Industries and Associations (EFPIA). EFPIA patient organisation code of practice on relationships between the pharmaceutical industry and patient organisations 2011 https://www.efpia.eu/media/24310/3c efpia-code-of-practice-onrelationships-pharmapluspt-orgs.pdf

24 Medicines Australia. Code of conduct, 19th edition, 2019. Available: https://www.medicinesaustralia.com.au/code-of-conduct/code-ofconduct-current-edition/

25 Karas L, Feldman R, Bai G. Pharmaceutical industry funding to patient-advocacy organizations: a cross-national comparison of disclosure codes and regulation. Hastings Int'/ \& Comp L Rev 2019;42:453

26 Consumers Health Forum, Medicines Australia. Working together guide, 3rd ed, 2015. Available: https://medicinesaustralia.com.au/ community/working-together-guide/

27 National Voices, The Association of the British Pharmaceutical Industry. Working together, delivering for patients, 2015. Available: https://www.nationalvoices.org.uk/publications/our-publications/ working-together-delivering-patients-guide-collaboration-betweencharities-and

28 Jones $\mathrm{K}$. In whose interest? relationships between health consumer groups and the pharmaceutical industry in the UK. Sociol Health IIIn 2008;30:929-43.

29 Leto di Priolo S, Fehervary A, Riggins P, et al. Assessing stakeholder opinion on relations between cancer patient groups and pharmaceutical companies in Europe. Patient 2012;5:127-39.

30 Parker L, Fabbri A, Grundy Q, et al. "Asset exchange"-interactions between patient groups and pharmaceutical industry: Australian qualitative study. BMJ 2019;367:16694.

31 Baggott R, Allsop J, Jones K. Chapter 8: the pharmaceutical industry. speaking for patients and carers: health consumer groups and the policy process. Basingstoke: Palgrave, 2005: 185-204.

32 Lau E, Fabbri A, Mintzes B. How do health consumer organisations in Australia manage pharmaceutical industry sponsorship? A crosssectional study. Aust. Health Review 2019;43:474-80.

33 Colombo C, Mosconi P, Villani W, et al. Patient organizations' funding from pharmaceutical companies: is disclosure clear, complete and accessible to the public? an Italian survey. PLoS One 2012;7:e34974

34 Rose SL. Patient advocacy organizations: institutional conflicts of interest, trust, and trustworthiness. J Law Med Ethics 2013;41:680-7.

35 Frith L. Symbiotic empirical ethics: a practical methodology. Bioethics 2012;26:198-206.

36 Ives J, Dunn M, Cribb A, eds. Empirical bioethics: theoretical and practical perspectives. Cambridge: Cambridge University Press, 2017.
37 Mason J. Qualitative researching. 2nd ed. Los Angelos: Sage, 2012.

38 Carter S. Enacting internal coherence: as a path to quality in qualitative inquiry. In: Higgs J, Cherry N, Macklin R, eds. Researching practice: a discourse on qualitative methodologies. Rotterdam: Sense publishers, 2010: 143-52.

39 Charmaz K. Constructing grounded theory. 2nd ed. Los Angelos: Sage, 2014.

40 Ritchie J, Lewis J. Qualitative research practice: a guide for social science students and researchers. London: Sage, 2003.

41 Tong A, Sainsbury P, Craig J. Consolidated criteria for reporting qualitative research (COREQ): a 32-item checklist for interviews and focus groups. Int J Qual Health Care 2007;19:349-57.

42 Parker L, Karanges EA, Bero L. Changes in the type and amount of spending disclosed by Australian pharmaceutical companies: an observational study. BMJ Open 2019;9:e024928.

43 Fabbri A, Swandari S, Lau E, et al. Pharmaceutical industry funding of health consumer groups in Australia: a cross-sectional analysis. Int $J$ Health Serv 2019;49:273-93.

44 Duration IA. Dominance and depth in telephone and face-toface interviews: a comparative exploration. Int J Qual Methods 2011;10:202-20.

45 Sturges JE, Hanrahan KJ, Telephone C. Comparing telephone and face-to-face qualitative interviewing: a research note. Qualitative Research 2004;4:107-18.

46 Evidence \& Policy \& Influence Collaborative, Health Consumers NSW, Consumers Health Forum. Consumer-pharmaceutical industry relationships: building trust and transparency, 2020. Available: http:// www.hensw.org.au/trust-and-transparency/

47 Parker L, Brown A, Wells L. Building trust and transparency: health consumer organisation-pharmaceutical industry relationships. Aust Health Rev 2020. doi:10.1071/AH20206. [Epub ahead of print: 03 Dec 2020].

48 Saumure K, Given L, saturation D. Data saturation. In: Given L, ed. The SAGE encyclopedia of qualitative research methods. Thousand Oaks, CA: Sage Publications, 2008: 196. 196.

49 Medicines Australia. Code of conduct, 18th ed, 2015. Available: http://www.medicinesaustralia.com.au/code-of-conduct/code-ofconduct-current-edition

50 Rose SL, Highland J, Karafa MT, et al. Patient advocacy organizations, industry funding, and conflicts of interest. JAMA Intern Med 2017;177:344-50

51 Grande D, Frosch DL, Perkins AW, et al. Effect of exposure to smal pharmaceutical promotional items on treatment preferences. Arch Intern Med 2009;169:887-93.

52 DeJong C, Aguilar T, Tseng C-W, et al. Pharmaceutical IndustrySponsored meals and physician prescribing patterns for Medicare beneficiaries. JAMA Intern Med 2016;176:1114-10.

53 Grundy Q, Bero LA, Malone RE. Marketing and the most trusted profession: the invisible interactions between registered nurses and industry. Ann Intern Med 2016;164:733-9.

54 Marks J. Chapter 8: towards systemic ethics. The perils of partnership: industry influence, institutional integrity, and public health. New York: Oxford University Press, 2019: 122-40.

55 Italian Medicines Agency (AIFA) Research \& Development Working Group. Feasibility and challenges of independent research on drugs: the Italian medicines Agency (AIFA) experience. Eur J Clin Invest 2010;40:69-86. 